\title{
EDITORIAL
}

\section{CAN INNOVATION BE TAUGHT?}

\author{
Andreea Ștefania Racoviță ${ }^{1}$, S. Paik², C. T. Milian ${ }^{3}$ \\ 1 'Carol Davila' University of Medicine and Pharmacy, Bucharest \\ ${ }^{2}$ Heidelberg University School of Medicine, Heidelberg \\ ${ }^{3}$ The Institute of Mechatronics and Precision Mechanics- Prototyping Department, Bucharest
}

'We live in a world where change is exponential and we are helping to prepare students for jobs that don't yet exist, using technologies that have not yet been invented, in order to solve problems that we don't know are problems yet'- Arti Kumar [1]

Progress in the medical field is driven by innovation in technology. This holds true all the more when looking at the surgical discipline: for centuries, better visualization allowed for greater understanding and, ultimately, more advanced instruments, procedures and outcomes. But, as the growth of technology is accelerating even further, making use of the full potential of emerging technologies has become more and more difficult. A promising way to overcome this challenge is the revolution of our medical education system.

The IRCAD center, recognized worldwide as the reference center for Minimally Invasive Surgery, leverages this interest through a unique philosophy of incubating talents for surgical innovation. As such, the B.E.S.T. (Business Engineering and Surgical Technology) teaching method consists of two components: online and on-site.

Students access MOOCs (Massive Open Online Courses) by world-renowned faculty and corresponding quizzes, along with the possibility of interacting in a chat with the speaker [2].

Afterwards, among the online participants from all around the world, 15 medical and 15 engineering and/or business students are selected each year for an intensive onsite experience based on the online course results, curriculum vitae and a letter of intent. Participants learn from a mixture of workshops in engineering and interventional radiology, form entrepreneurship team projects, train in laparoscopy, robotic surgery and flexible endoscopy on living swine models and simulators.

Most remarkably, despite the course being free of charge and providing such a vast variety of skills, the number of participants compared to that of faculty members is yet in favor of the latter with a ratio of 30:34. Finally, experts such as: surgeons, engineers, entrepreneurs, venture capitalists and scientists assess and award the delivered team projects and provisional patents are filed. Laparoscopy skills are also quantified and rewarded. The method has been proven to be well received and successful in improving students' performances, regardless of their background [3-4]. 
When provided with the right resources, people are empowered to start wondering. Doubt and fear of failure recede in the face of the possibilities lying within the challenges. Thus, informing about this innovative teaching format serves not only as an invitation for students, but also calls for action among professionals in Romania to step to the forefront and lead the way in early medical education by collaborating and establishing the needed infrastructure.

\section{References}

[1]A. Kumar, Personal, Academic and Career Development in Higher Education, 2007th ed. Routledge.

[2]"B.E.S.T. | Business Engineering and Surgical Technologies | The Society that connects you to Surgery." [Online]. Available: http://www.best-innovation.eu/. [Accessed: 07-Oct-2018].

[3]"Globalization of Undergraduate Surgical Education: A Unique Educational Experience at the Ircad France. - SAGES Abstract Archives." [Online]. Available: https://www.sages.org/ meetings/annualmeeting/abstracts-archive/globalization-of-undergraduate-surgical-education-a-unique-educationalexperience-at-the-ircad-france/. [Accessed: 07-Oct-2018].

[4]"One Size Fits All? the New Surgical Innovation Philosophy - SAGES Abstract Archives." [Online]. Available: $\quad$ https://www.sages.org/meetings/annual-meeting/abstracts-archive/one-size-fits-all-the-newsurgical-innovation-philosophy/. [Accessed: 07-Oct-2018]. 